\title{
Apigenin neutralizes the inhibitory effect of inflammation on the osteogenic differentiation of human mesenchymal stem cells
}

\author{
Azita Asadi \\ Isfahan University of Medical Sciences and Health Services School of Pharmacy and Pharmaceutical \\ Sciences \\ Farjam Goudarzi \\ Kermanshah University of Medical Sciences

\section{Mustafa Ghanadian} \\ Isfahan University of Medical Sciences and Health Services School of Pharmacy and Pharmaceutical \\ Sciences \\ Adel Mohammadalipour ( $\nabla$ mohammadalipour@pharm.mui.ac.ir ) \\ Isfahan University of Medical Sciences and Health Services School of Pharmacy and Pharmaceutical \\ Sciences https://orcid.org/0000-0002-2598-9439
}

\section{Research Article}

Keywords: Apigenin, NLRP3, Inflammation, RUNX2, Mesenchymal Stem Cells, Lipopolysaccharide

Posted Date: March 15th, 2021

DOI: https://doi.org/10.21203/rs.3.rs-283695/v1

License: (c) (i) This work is licensed under a Creative Commons Attribution 4.0 International License. Read Full License 


\section{Abstract}

Background: The stimulating effects of apigenin on mesenchymal stem cells (MSCs) osteogenesis, as well as the anti-inflammatory effect of this flavonoid, have been identified. In this study, osteogenic differentiation was investigated under inflammatory conditions and treatment with apigenin.

Methods and Results: Along with osteogenic differentiation of MSCs, they became inflamed with LPS/PA, and treated simultaneously with apigenin. The degree of differentiation was assessed by alizarin red staining and alkaline phosphatase (ALP) activity. Also, gene expression of NLRP3 and RUNX2 was performed along with protein expression of IL-1 $\beta$. Significant increase in NLRP3 and IL-1 $\beta$ were observed in MSCs when exposed to LPS/PA ( $p<0.01)$. Also, the osteogenesis was significantly decreased $(p<0.01)$. Apigenin treatment induced significantly higher gene expression of RUNX2, the activity of ALP, and cell staining $(p<0.01)$ which were also associated with reduced inflammation in these cells.

Conclusions: The effectiveness of apigenin on osteogenesis under inflammatory conditions was cautiously observed.

\section{Introduction}

Improve general health and reduced fertility, have increased life expectancy. Therefore, ageassociated diseases such as cardiovascular and neurodegenerative diseases, cancer, osteoporosis, and other bone-related diseases are more threatening today [1]. Osteoporosis, as a diverse genetic and metabolic bone disease, is one of the most important public health issues characterized by bone loss, bone density, and bone mass [2]. This disorder, commonly referred to as postmenopausal osteoporosis (PMOP) in women over fifty years, is associated with fracture and fat infiltration [3]. The real cause of it is due to an imbalance between the activity of osteoblasts (bone-forming cells) [4] and osteoclasts (bone cells) and a decrease in the differentiation potential of bone marrow mesenchymal stem cells [5]. In fact, in this case, this differentiation potential goes toward adipogenesis, which is associated with a significant change of cells from osteocytes to adipocytes [6].

Age, gender, inactivity, smoking, and alcohol are factors affecting osteoporosis [3]. The process of this disorder is associated with increased inflammation, especially the activation of nlrp3 Inflammasome [7]. If aging is accompanied by an increase in the basal level of inflammation, potentially impairs bone formation [8]. Thus, activation of NLRP3 inflammatory as an intracellular protein complex involved in the innate immune response increases adipogenesis and suppresses osteogenesis [7]. As a result, by controlling the inflammatory mechanism, including Nlrp3 Inflammasome, it seems that the behavior of stem cells can be regulated.

Anti-inflammatory effects of polyphenolic compounds have been reported with their effects in the treatment of diseases such as osteoporosis [9]. Among them, apigenin (4', 5, 7-Terry Hydroxy flavone) is a member of the flavonoid family that has potential anti-cancer, anti-inflammatory, antimicrobial and antioxidant properties [10]. 
Previous studies have shown that apigenin significantly downregulates TNF- $\alpha$, IL-6, and IL-1 $\beta$ 's mRNA levels in LPS activated mouse macrophages [11]. It also inhibits LPS-induced IL-1 $\beta$ by interfering with NLRP3 inflammasome and also decreases IL-6 and IL-1 $\beta$ production through ERK1 /2 [12].

Anti-osteoclastogenic effects of this compound [13] have also been reported to be associated with increased expression of osteoblast differentiation genes such as alkaline phosphatase, collagen, osteopontin, and BMP in osteoblasts [14]. Apigenin was also able to induce osteogenesis of hMSCs by increasing the expression of Runt-related transcription factor 2 (RUNX2) and osterix (Osx) $[15,16]$. These results suggest that apigenin enhances osteogenesis of hMSCs from osteoblast precursors to terminal differentiation states.

According to the above, the anti-inflammatory effect of apigenin along with its effect on stimulating osteogenesis has been identified. Due to this, and the role of inflammation in inhibiting osteogenesis, the protective effect of this compound against LPS/PA-induced osteoporosis, as well as its osteogenic stimulatory effect, was investigated.

\section{Methods}

\section{Cell culture}

Mesenchymal stem cells were enzymatically isolated from abdominal adipose tissue isolated from women who underwent liposuction procedure. Due to the use of disposable abdominal fat, this was confirmed by the ethics committee of Isfahan University of Medical Sciences. The MSC isolation steps included washing the adipose tissue with PBS (0.1 M, pH=7.4) - penicillin-streptomycin (10000 U-10000 $\mathrm{mg} / \mathrm{ml}$ ) three times and digesting the tissue with collagenase type I $(1 \mathrm{mg} / \mathrm{ml}$ in PBS) (Thermo Fisher Scientific, USA) followed by lysis of erythrocytes by RBC lysis buffer ( $155 \mathrm{mM} \mathrm{NH}_{4} \mathrm{Cl}, 12 \mathrm{mM} \mathrm{NaHCO}_{3}$, and $0.1 \mathrm{mM}$ EDTA) and centrifugation ( $800 \times \mathrm{g}$ for five minutes). The isolated cells were maintained at $37^{\circ} \mathrm{C}$ and $5 \% \mathrm{CO}_{2}$ in self-renewal medium (DMEM-F12 $+10 \% \mathrm{FBS}+1 \% \mathrm{P} / \mathrm{S}$ (Thermo Fisher Scientific, USA). The medium was changed every three days and the cells were passaged after each filling of the flask. After four passages, the cells were differentiated under the following conditions. For osteogenesis, the self-renewal medium was changed by an osteogenic medium contained $100 \mathrm{nM}$ dexamethasone, 10 $\mathrm{mM}$ ß-glycerophosphate, and $0.05 \mathrm{mM} \mathrm{L-ascorbic} \mathrm{acid-2-phosphate.} \mathrm{For} \mathrm{chondrogenesis,} \mathrm{the}$ chondrogenic medium was used which contained the same complete medium and dexamethasone (100 $\mathrm{nM}$ ), L-proline (40 $\mu \mathrm{g} / \mathrm{ml}$; Merck Millipore Corporation, Istanbul, Turkey), L-ascorbic acid 2-phosphate (50 $\mu \mathrm{g} / \mathrm{ml}$; Sigma-Aldrich, Germany), and TGF- $\beta 3$ (10 ng/ml; BioLegend ${ }^{\grave{O}}$, Istanbul-Turkey). For adipogenesis, the adipogenic medium contained dexamethasone $(1 \mu \mathrm{M})$, indomethacin $(100 \mu \mathrm{M})$, insulin $(10 \mu \mathrm{g} / \mathrm{mL})$, and 3-isobutyl-1-methylxanthine (IBMX; 0.5 mM) (All from Sigma-Aldrich Co. Ltd., Dorset, UK) [17,18].

\section{hMSCs immunophenotyping and multipotency assays}

The cell identification was done by three lineage differentiation and FACS Immunophenotyping with positive (CD73, CD90, CD105) and negative (CD34 and CD45) CD markers include. For isotype controls, 
rabbit polyclonal IgG and rat IgG2b were used (all BD Biosciences, San Jose, USA) [17]. In summary, the cells from passage four were trypsinized and transferred to a $15 \mathrm{ml}$ tube and fixed with $4 \%$ paraformaldehyde. Finally, surface CD markers were characterized using a flow cytometry device (Partec, Germany) [18].

\section{MTS assay}

The toxicity effects of apigenin in the whole period of treatment was done by cell viability assay using an MTS assay kit (Abcam, Cambridge, UK). Accordingly, after the growth of cells in a 96-well plate at the density of $5 \times 103$, they were treated with apigenin (1-100 $\mu \mathrm{M})$ for 1, 2, 3, 7, and 14 days. Then, using 20 $\mu \mathrm{L} /$ well MTS reagent for four hours at $37^{\circ} \mathrm{C}$ the absorbance was read at $490 \mathrm{~nm}$ in a microplate reader (BioTek Instruments, USA) [17].

\section{Osteogenesis induction and treatment}

To evaluate the effect of apigenin on the expression of NLRP3 and interleukin induced by LPS and PA, MSCs were exposed to $0.1 \mathrm{mg}^{\mathrm{ml}} \mathrm{l}^{-1} \mathrm{LPS} / 0.25 \mathrm{mM} \mathrm{PA}$ and $1 \mathrm{mg} \cdot \mathrm{ml}^{-1} \mathrm{LPS} / 0.25 \mathrm{mM}$ PA for 72 hours. Then, different concentrations of apigenin $(25$ and $50 \mu \mathrm{M})$ were added to the medium for 14 days. To compare the effect of apigenin on osteogenesis in inflammatory conditions, cells were first exposed to LPS/PA for 72 hours and then induced osteogenesis for 21 days while being treated simultaneously with apigenin for 14 days. The protocol for inducing osteogenesis, inflammation, and treatment has been based on the assessment of cell viability and previous studies $[7,19,20]$

\section{Alizarin red staining}

Briefly, cells cultured on a 24 well plate were washed with PBS, fixed with $4 \%$ formaldehyde, and then stained with $0.5 \%$ Alizarin Red in deionized water $(\mathrm{pH}=4.1)$ for 30 minutes at room temperature [15].

\section{Evaluation of ALP activity}

The cells cultured on the plate were washed with PBS and lysed using lysis buffer $(20 \mathrm{mM}$ Tris $-\mathrm{HCl}(\mathrm{pH}$ 7.5), $150 \mathrm{mM} \mathrm{NaCl}$, and 1\% Triton X-100). ALP activity was measured by laboratory kits and protein content was measured by the bicinchoninic acid (BCA) method [21].

\section{Measurement of interleukin-1 $\beta$ by ELISA}

The amount of interleukin-1 $\beta$ released in the culture medium was measured using a human IL-1 $\beta$ ELISA kit in cells cultured on a 24 well plate (Carmania Pars Gene, Iran).

\section{Gene expression evaluation of NLRP3 and RUNX2}

The flask containing co-culture of apigenin, LPS/PA of all groups were lysed using Kiazol reagent (Kiazist, Iran) for RNA isolation. The concentration and integrity of isolated RNA were then analyzed using a microplate reader (BioTek Instruments, USA). They were reverted to complementary DNA using a cDNA 
synthesis kit (gene all, Seoul Korea). NLRP3 and RUNX2 gene expression was amplified by quantitative real-time PCR (qPCR) through an $A B I 7500$ sequence detection system (Applied Biosystems). The forward and reverse primers include; RUNX2; F, 5' - ACGAGGCAAGAGTTTCACCT-3', R, 5'-

AGCTTCTGTCTGTGCCTTCT-3', NLRP3; F, 5' - GATCTTCGCTGCGATCAACAG-3', R, 5' -

CGTGCATTATCTGAACCCCAC-3'. Expression of these genes was performed based on RPIl reference gene with primer sequence RPII; F, 5' - GCACCATCAAGAGAGTCCAGT-3', R, 5- ATTTGATGCCACCCTCCGTCA-3 based on cycle threshold (Ct) 2- $(\Delta \Delta \mathrm{Ct}$ ) using SYBR green qPCR master mix (Odense $\mathrm{M}$, Denmark) [22].

\section{Statistical analyses}

Data analyses were performed using SPSS software (SPSS version 16.0) and GraphPad Prism version 6.0 (GraphPad Software, San Diego, CA). Statistical significance was performed using one-way analysis of variance (ANOVA) followed by post hoc Tukey and $p<0.05$ was considered as statistically significant.

\section{Results}

\section{Mesenchymal stem cell confirmation}

Mesenchymal stem cell confirmation was performed by examining surface CD markers as well as the ability to differentiate cells into three categories: adipocytes, osteocytes, and chondrocytes (Fig. 1). According to Fig. 1, the results showed high expression of positive markers (CD73; 86.9\%, CD90; 88.7\% and CD105; 88.3\%), and low expression of negative markers (CD34; $2.41 \%$ and CD 45; $2.06 \%$ ), which along with their high ability to differentiate into these three categories by specific staining confirmed cell type.

\section{Cell viability assay}

Initially, a cell viability test was performed by multiple doses of apigenin ( 1 to $100 \mu \mathrm{M}$ ) by the MTS method (Fig.2). The results showed that in a 14-day period of cell treatment, different doses had no toxic effect.

\section{LPS/PA caused inflammation in the MSCs.}

To evaluate the response of MSCs to inflammatory agents, they were inflamed by LPS/PA at different doses and the gene expression of NLRP3 along with the protein level of IL-1 $\beta$ was examined (Figure 3 ). LPS / PA-induced inflammation was observed as a significant increase in NLRP3 gene expression and IL$1 \beta$ levels compared with controls $(p<0.001)$. The anti-inflammatory effect of apigenin was also investigated by examining NLRP3 gene expression and IL-1 $\beta$ levels under the influence of this compound. Statistically apigenin in both concentrations significantly decrease protein level of IL-1 $\beta$ and downregulated gene expression of NLRP3 compared to cells that didn't receive the compound $(p<0.001)$.

\section{LPS/PA-induced inflammasome suppresses osteogenesis in MSCs.}


The effect of apigenin and LPS/PA on osteogenesis were subsequently examined (Figure 3). For this purpose, ALP activity, RUNX2 and NLPRP3 gene expression, and IL-1 $\beta$ protein were determined. As shown in Figure 3A, the stimulatory effect of apigenin on osteogenesis in non-inflammatory conditions was observed with increasing ALP activity $(p<0.01)$, and increased RUNX2 expression $(p<0.001)$, which was statistically significant. Inflammation, induced by LPS/PA was associated with a significant increase in the expression of the NLRP3 gene and IL-1 $\beta$ protein ( $<<0.001$; group OSX+LPS/PA v.s OSX). These inflammatory conditions were also associated with a significant reduction in osteogenesis, which was observed by measuring RUNX2 expression and ALP activity in comparison with the control group $(p<0.001)$. Interestingly, also in inflammatory conditions, apigenin was able to improve ossification at both concentrations, citing a significant increase in RUNX2 expression and ALP activity, compared with the untreated group ( $p<0.01$ v.s OSX+LPS/PA). To confirm their effects on the degree of osteogenesis, the differentiation of mesenchymal stem cells into osteocytes was evaluated by evaluating alizarin red staining. In staining, increased bone calcium staining was observed in treatment with $50 \mu \mathrm{M}$ apigenin compared to the untreated group in both inflammatory and non-inflammatory conditions.

\section{Discussion}

The hypothesis of this study was based on the relationship between inflammation and osteoporosis. Osteoporosis is a chronic disease that occurs in old age, especially in postmenopausal women, due to decreased estrogen secretion, which is associated with loss of bone mass and increased fat penetration into the bone marrow [23]. Also, the role of inflammation on bone turnover and osteoporosis has been identified [24], which is also strongly associated with menopause [25]. NLRP3-based inflammation has also been shown to play an important role in this process [7].

If so, targeted interventions to modulate inflammation are one of the potential strategies to optimize bone repair in the elderly [8]. Mesenchymal stem cells play an important role in bone modeling and remodeling by forming basic osteoblasts while maintaining a balance between bone formation and resorption [26].

Accordingly, in the present study, mesenchymal stem cells were inflamed with LPS/PA in the osteogenic differentiation and their behavior under the influence of inflammation was examined. As expected, inflammation disrupted the process of this differentiation. This was consistent with previous information about the association of aging with inflammation and subsequent osteoporosis [24]. Also, the effect of lipopolysaccharide-induced inflammation on inhibition of osteogenesis has been accurately expressed in other studies [27,7].

These changes in osteogenesis were characterized by changes in RUNX2 gene expression, ALP activity, and calcium deposition stained by Alizarin Red. RUNX2 transcription, as a major osteogenic factor, is a nuclear transcription factor and regulator of bone differentiation [28]. The essential role of the RUNX2 transcription factor in this process has been proven in various molecular and genetic studies [29]. ALP is an early marker of osteoporosis that plays an important role in bone formation and its peak activity 
indicates differentiation [30], Therefore, changes in these cases indicate an inhibitory effect of inflammation on the osteogenesis.

In the present study, the anti-inflammatory effects of apigenin were evaluated. Accordingly, while the stem cells were inflamed with LPS/PA, the anti-inflammatory effects of this flavonoid compound were observed via significant down-regulation of NLRP3 and IL-1 $\beta$ when compared with the non-treatment group.

The anti-inflammatory role of flavonoid derivatives by inhibiting NLRP3 inflammasome has been well demonstrated [31]. Apigenin in particular has an anti-inflammatory effect by inhibiting oligomerization of inflammasome components by blocking Syk and Pyk2 signaling pathways and other pathways [31]. NLRP3 as the most important member of this complex, and sensors of pathogen-associated molecular patterns (PAMPs), facilitates interaction with caspase-1 and is necessary for IL-1 $\beta$ processing [32]. Therefore, down-regulation of its expression as well as IL-1 $\beta$ secretion showed its anti-inflammatory activity.

Apigenin, as a plant flavone, has also shown its osteogenic effects by inhibiting osteoclasts, prevent bone loss, and stimulation of osteogenic differentiation of hMSCs in various studies [33,34,15]. On the other hand, as mentioned, the anti-inflammatory effect of this flavonoid has been identified in various studies $[35,31]$, which is done by inhibiting the NLRP3 inflammasome [35,36,31]. In the present study, the effect of inflammation on bone differentiation and the effect of apigenin on ossification stimulation were investigated, most likely through inhibition of inflammation. These effects were based on altering the expression of the NLRP3 inflammasome gene and the amount of IL-1 $\beta$ along with the stimulation of ossification based on the study of RUNX2 gene expression, ALP activity, and Alizarin Red staining. Therefore, the stimulatory effect of apigenin on osteogenesis can be exerted in two ways: reducing NLRP expression and inflammation, and the intrinsic effect of apigenin on differentiation.

According to previous reports, in 2005, more than 2 million people suffered from osteoporotic fractures, which will bring a lot of treatment costs by 2025 due to the aging of the population [37]. The drugs developed have two functions: inhibiting bone resorption or stimulating bone formation, which lead to many problems, from inhibiting bone formation in long-term use, gastrointestinal and hormonal problems to muscle pain, and finally osteosarcoma [38-40]. Therefore, the importance of developing a safer compound based on natural origin is important. Due to the limitations of the present study concerning the evaluation of adipogenic pathway, as well as using pathway inhibitors, more detailed assessments have been considered to obtain more complete results in subsequent studies.

In conclusion, our study showed the stimulatory effect of apigenin on osteogenesis in inflammatory conditions. This could be due to the anti-inflammatory effect of this compound, as well as the inherent stimulatory effect of apigenin on osteogenesis. It also confirms the role of inflammation in osteogenesis and the importance of inhibiting inflammation in this process. The importance of using flavonoids with a focus on the anti-inflammatory role of these compounds was also identified in this study. 


\section{Declarations}

Conflicts of interest None.

\section{Authors' contributions}

All authors contributed to the study conception and design. Material preparation, data collection and analysis were performed by [Azita Asadi], [Farjam Goudarzi], [Mustafa Ghanadian] and [Adel Mohammadalipour]. The first draft of the manuscript was written by [Azita Asadi] and all authors commented on previous versions of the manuscript. All authors read and approved the final manuscript

\section{Consent to participate}

All authors whose names appear on the submission

1) made substantial contributions to the conception or design of the work; or the acquisition, analysis, or interpretation of data; or the creation of new software used in the work;

2) drafted the work or revised it critically for important intellectual content;

3) approved the version to be published; and

4) agree to be accountable for all aspects of the work in ensuring that questions related to the accuracy or integrity of any part of the work are appropriately investigated and resolved.

\section{Consent for publication}

Submission of a manuscript implies: that the work described has not been published before; that it is not under consideration for publication anywhere else; that its publication has been approved by all coauthors, if any, as well as by the responsible authorities tacitly or explicitly at the institute where the work has been carried out. The publisher will not be held legally responsible should there be any claims for compensation.

\section{Funding}

This work was supported as a master's thesis by Deputy for Research and Technology of Isfahan University of Medical Sciences (Ethic No. IR.MUI.RESEARCH.REC.1397.463).

\section{Acknowledgment}

This study was conducted at Isfahan University of Medical Sciences by a project with the ethical code IR.MUI.RESEARCH.REC.1397.463.

\section{References}


1. Niccoli T, Partridge L (2012) Ageing as a Risk Factor for Disease. Current Biology 22 (17):R741-R752. doi:https://doi.org/10.1016/j.cub.2012.07.024

2. Yu B, Wang C-Y (2016) Osteoporosis: the result of an 'aged'bone microenvironment. Trends in molecular medicine 22 (8):641-644. doi:https://doi.10.1016/j.molmed.2016.06.002

3. Bultink IE, Lems WF (2013) Osteoarthritis and osteoporosis: what is the overlap? Current rheumatology reports 15 (5):328. doi:https://doi.10.1007/s11926-013-0328-0

4. Rachner TD, Khosla S, Hofbauer LC (2011) Osteoporosis: now and the future. The Lancet 377 (9773):1276-1287. doi:https://doi.10.1016/S0140-6736(10)62349-5

5. Li R, Liang L, Dou Y, Huang Z, Mo H, Wang Y, Yu B (2015) Mechanical strain regulates osteogenic and adipogenic differentiation of bone marrow mesenchymal stem cells. BioMed research international 2015. doi:https://doi.10.1155/2015/873251

6. Rosen CJ, Bouxsein ML (2006) Mechanisms of disease: is osteoporosis the obesity of bone? Nature clinical practice Rheumatology 2 (1):35-43. doi:https://doi.10.1038/ncprheum0070

7. Wang L, Chen K, Wan X, Wang F, Guo Z, Mo Z (2017) NLRP3 inflammasome activation in mesenchymal stem cells inhibits osteogenic differentiation and enhances adipogenic differentiation. Biochemical and biophysical research communications 484 (4):871-877. doi:https://doi.10.1016/j.bbrc.2017.02.007

8. Gibon E, Lu LY, Nathan K, Goodman SB (2017) Inflammation, ageing, and bone regeneration. Journal of orthopaedic translation 10:28-35. doi:https://doi.10.1016/j.jot.2017.04.002

9. Weaver CM, Alekel DL, Ward WE, Ronis MJ (2012) Flavonoid intake and bone health. Journal of nutrition in gerontology and geriatrics 31 (3):239-253.

doi:https://doi.10.1080/21551197.2012.698220

10. Shukla S, Gupta S (2010) Apigenin: a promising molecule for cancer prevention. Pharmaceutical research 27 (6):962-978. doi:https://doi.10.1007/s11095-010-0089-7

11. Nicholas C, Batra S, Vargo MA, Voss OH, Gavrilin MA, Wewers MD, Guttridge DC, Grotewold E, Doseff Al (2007) Apigenin blocks lipopolysaccharide-induced lethality in vivo and proinflammatory cytokines expression by inactivating NF-KB through the suppression of p65 phosphorylation. The Journal of Immunology 179 (10):7121-7127

12. Zhang X, Wang G, Gurley EC, Zhou H (2014) Flavonoid apigenin inhibits lipopolysaccharide-induced inflammatory response through multiple mechanisms in macrophages. PLoS One 9 (9):e107072. doi:https://doi.10.1371/journal.pone.0107072

13. Bandyopadhyay S, Lion J-M, Mentaverri R, Ricupero DA, Kamel S, Romero JR, Chattopadhyay N (2006) Attenuation of osteoclastogenesis and osteoclast function by apigenin. Biochemical pharmacology 72 (2):184-197. doi:https://doi.10.1016/j.bcp.2006.04.018

14. Choi E-M (2007) Apigenin increases osteoblastic differentiation and inhibits tumor necrosis factor-ainduced production of interleukin-6 and nitric oxide in osteoblastic MC3T3-E1 cells. Die PharmazieAn International Journal of Pharmaceutical Sciences 62 (3):216-220. doi:https://doi.10.1691/ph.2007.3.6629 
15. Zhang X, Zhou C, Zha X, Xu Z, Li L, Liu Y, Xu L, Cui L, Xu D, Zhu B (2015) Apigenin promotes osteogenic differentiation of human mesenchymal stem cells through JNK and p38 MAPK pathways. Molecular and cellular biochemistry 407 (1-2):41-50. doi:https://doi.10.1007/s11010-0152452-9

16. Welch AA, Hardcastle AC (2014) The effects of flavonoids on bone. Current osteoporosis reports 12 (2):205-210. doi:https://doi.10.1007/s11914-014-0212-5

17. Goudarzi F, Tayebinia H, Karimi J, Habibitabar E, Khodadadi I (2018) Calcium: A novel and efficient inducer of differentiation of adipose-derived stem cells into neuron-like cells. Journal of cellular physiology 233 (11):8940-8951. doi:https://doi.10.1002/jcp.26826

18. Goudarzi F, Sarveazad A, Mahmoudi M, Mohammadalipour A, Chahardoli R, Malekshah OM, Karimi Gorgani S, Saboor-Yaraghi AA (2018) Combined effect of retinoic acid and calcium on the in vitro differentiation of human adipose-derived stem cells to adipocytes. Archives of physiology and biochemistry 124 (2):109-118. doi:10.1080/13813455.2017.1367009

19. Wang F, Zhou R-J, Zhao X, Ye H, Xie M-L (2018) Apigenin inhibits ethanol-induced oxidative stress and LPS-induced inflammatory cytokine production in cultured rat hepatocytes. Journal of Applied Biomedicine 16 (1):75-80. doi:https://doi.org/10.1016/j.jab.2017.11.006

20. Ono M, Fujimori K (2011) Antiadipogenic effect of dietary apigenin through activation of AMPK in 3T3-L1 cells. Journal of agricultural and food chemistry 59 (24):13346-13352. doi:https://doi.10.1021/jf203490a

21. Suou K, Taniguchi F, Tagashira Y, Kiyama T, Terakawa N, Harada T (2011) Apigenin inhibits tumor necrosis factor $\alpha$-induced cell proliferation and prostaglandin $E 2$ synthesis by inactivating NFKB in endometriotic stromal cells. Fertility and sterility 95 (4):1518-1521.

doi:https://doi.10.1016/j.fertnstert.2010.09.046

22. Goudarzi F, Mohammadalipour A, Khodadadi I, Karimi S, Mostoli R, Bahabadi M, Goodarzi MT (2018) The Role of Calcium in Differentiation of Human Adipose-Derived Stem Cells to Adipocytes. Molecular biotechnology 60 (4):279-289. doi:10.1007/s12033-018-0071-x

23. Chen Y, Wang W, Yang L, Chen W, Zhang H (2018) Association between lipid profiles and osteoporosis in postmenopausal women: a meta-analysis. Eur Rev Med Pharmacol Sci 22 (1):1-9. doi:https://doi.10.26355/eurrev_201801_14093

24. Ginaldi L, Di Benedetto MC, De Martinis M (2005) Osteoporosis, inflammation and ageing. Immunity \& Ageing 2 (1):1-5. doi:https://doi.10.1186/1742-4933-2-14

25. Al-Daghri NM, Aziz I, Yakout S, Aljohani NJ, Al-Saleh Y, Amer OE, Sheshah E, Younis GZ, Al-Badr FBM (2017) Inflammation as a contributing factor among postmenopausal Saudi women with osteoporosis. Medicine (Baltimore) 96 (4):e5780-e5780. doi:https://doi.10.1097/MD.0000000000005780

26. Lin H, Sohn J, Shen H, Langhans MT, Tuan RS (2019) Bone marrow mesenchymal stem cells: Aging and tissue engineering applications to enhance bone healing. Biomaterials 203:96-110. doi:https://doi.10.1016/j.biomaterials.2018.06.026 
27. Li C, Li B, Dong Z, Gao L, He X, Liao L, Hu C, Wang Q, Jin Y (2014) Lipopolysaccharide differentially affects the osteogenic differentiation of periodontal ligament stem cells and bone marrow mesenchymal stem cells through Toll-like receptor 4 mediated nuclear factor KB pathway. Stem cell research \& therapy 5 (3):1-13. doi:https://doi.10.1186/scrt456

28. Coffman JA (2003) Runx transcription factors and the developmental balance between cell proliferation and differentiation. Cell Biology International 27 (4):315-324. doi:https://doi.org/10.1016/S1065-6995(03)00018-0

29. Gordeladze JO, Noël D, Bony C, Apparailly F, Louis-Plence P, Jorgensen C (2008) Transient downregulation of cbfa1/Runx 2 by RNA interference in murine $\mathrm{C} 3 \mathrm{H} 10 \mathrm{~T} 1 / 2$ mesenchymal stromal cells delays in vitro and in vivo osteogenesis, but does not overtly affect chondrogenesis. Experimental cell research 314 (7):1495-1506. doi:https://doi.10.1016/j.yexcr.2007.12.023

30. Bent-al-hoda Movahedi Najafabadi M, Abnosi H (2016) Boron induces early matrix mineralization via calcium deposition and elevation of alkaline phosphatase activity in differentiated rat bone marrow mesenchymal stem cells. Cell Journal (Yakhteh) 18 (1):62. doi:https://doi.10.22074/cellj.2016.3988

31. Lim H, Min DS, Park H, Kim HP (2018) Flavonoids interfere with NLRP3 inflammasome activation. Toxicology and applied pharmacology 355:93-102. doi:https://doi.10.1016/j.taap.2018.06.022

32. Tschopp J, Martinon F, Burns K (2003) NALPs: a novel protein family involved in inflammation. Nature reviews Molecular cell biology 4 (2):95-104. doi:https://doi.10.1038/nrm1019

33. Park JA, Ha SK, Kang TH, Oh MS, Cho MH, Lee SY, Park J-H, Kim SY (2008) Protective effect of apigenin on ovariectomy-induced bone loss in rats. Life sciences 82 (25-26):1217-1223. doi:https://doi.10.1016/j.lfs.2008.03.021

34. Goto T, Hagiwara K, Shirai N, Yoshida K, Hagiwara H (2015) Apigenin inhibits osteoblastogenesis and osteoclastogenesis and prevents bone loss in ovariectomized mice. Cytotechnology 67 (2):357365. doi:https://doi.10.1007/s10616-014-9694-3

35. Ai X-Y, Qin Y, Liu H-J, Cui Z-H, Li M, Yang J-H, Zhong W-L, Liu Y-R, Chen S, Sun T (2017) Apigenin inhibits colonic inflammation and tumorigenesis by suppressing STAT3-NF-KB signaling. Oncotarget 8 (59):100216. doi:https://doi.10.18632/oncotarget.22145

36. Li R, Wang X, Qin T, Qu R, Ma S (2016) Apigenin ameliorates chronic mild stress-induced depressive behavior by inhibiting interleukin-1 $\beta$ production and NLRP3 inflammasome activation in the rat brain. Behavioural brain research 296:318-325. doi:https://doi.10.1016/j.bbr.2015.09.031

37. Wang Z, Wang D, Yang D, Zhen W, Zhang J, Peng S (2018) The effect of icariin on bone metabolism and its potential clinical application. Osteoporosis International 29 (3):535-544. doi:https://doi.10.1007/s00198-017-4255-1

38. Jolette J, Attalla B, Varela A, Long GG, Mellal N, Trimm S, Smith SY, Ominsky MS, Hattersley G (2017) Comparing the incidence of bone tumors in rats chronically exposed to the selective PTH type 1 receptor agonist abaloparatide or PTH(1-34). Regulatory toxicology and pharmacology : RTP 86:356365. doi:https://doi.10.1016/j.yrtph.2017.04.001 
39. Vahle JL, Long GG, Sandusky G, Westmore M, Ma YL, Sato M (2004) Bone neoplasms in F344 rats given teriparatide [rhPTH(1-34)] are dependent on duration of treatment and dose. Toxicologic pathology 32 (4):426-438. doi:https://doi.10.1080/01926230490462138

40. Papapetrou PD (2009) Bisphosphonate-associated adverse events. Hormones (Athens, Greece) 8 (2):96-110. doi:https://doi.10.14310/horm.2002.1226

\section{Figures}
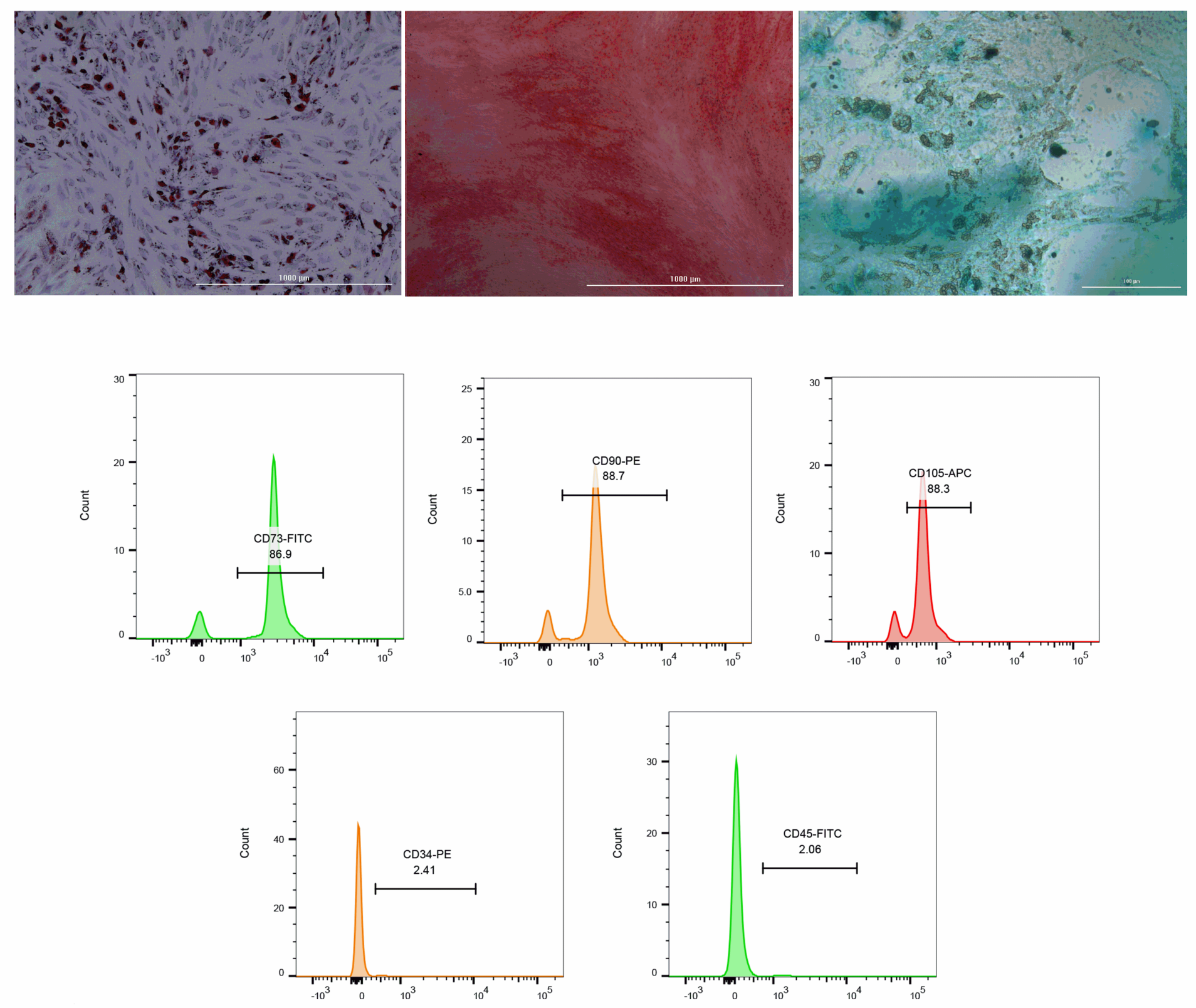

\section{Figure 1}

Confirmation of mesenchymal stem cells by determining surface markers and multi-potency properties of stem cells in differentiating into three cell lines: osteocytes, adipocytes, and chondrocytes. A; Flow 
cytometric analysis of the CD markers of human-derived MSCs. Accordingly, While a high percentage of cells was observed with CD73, CD90 and CD105, only $2.41 \%$ of cells were positive in CD34 and $2.06 \%$ were positive in CD45. B: Differentiation of these cells into adipocytes by Oil Red O (red spots) staining and into chondrocytes by glycosaminoglycan (GAG) staining using safranin and differentiation into osteocytes by alizarin red staining were observed.

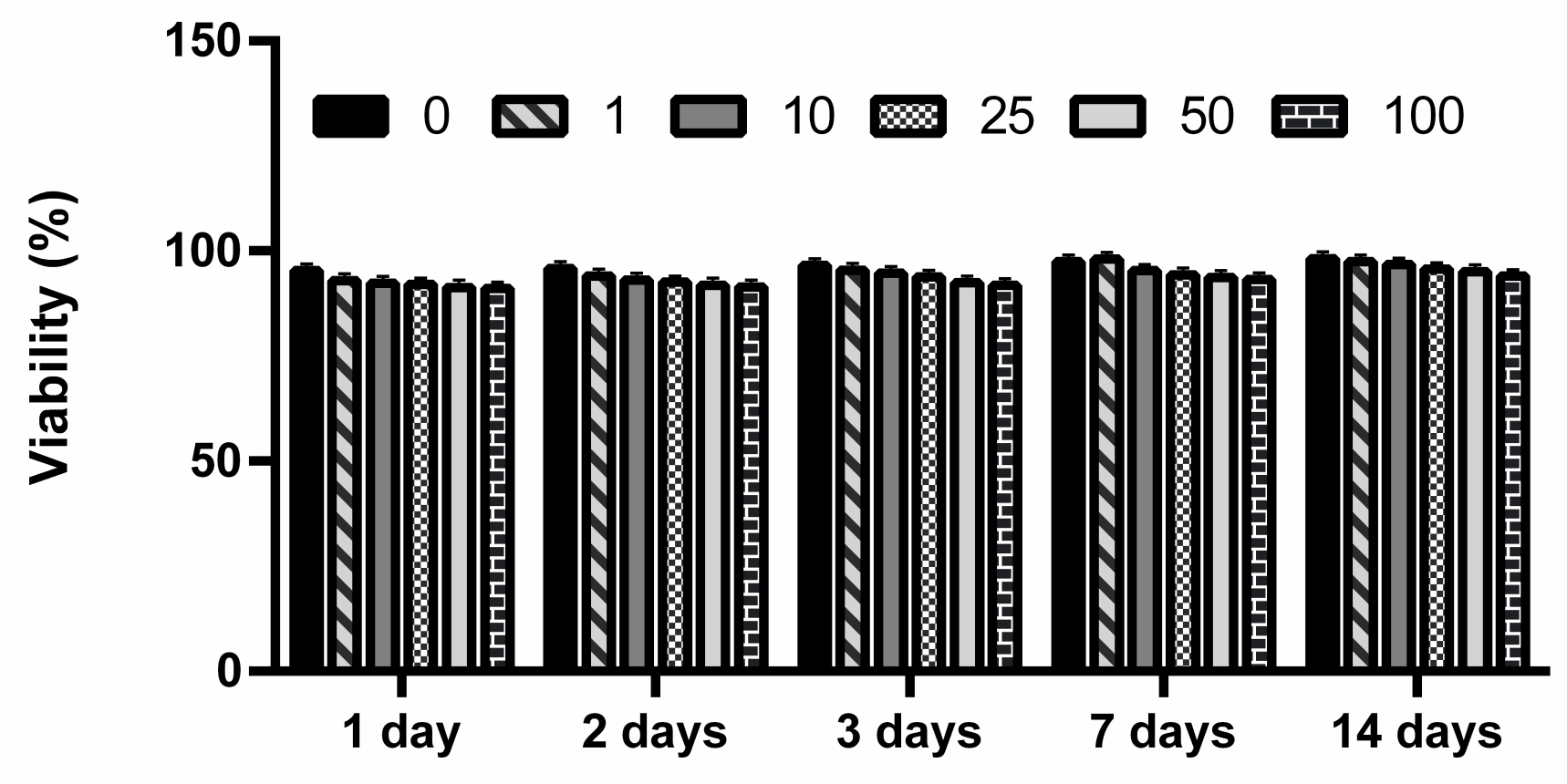

Apigenin concentration $(\mu \mathrm{M})$

Figure 2

Effect of apigenin on the viability of hMSCs. Different concentrations of apigenin ( $1 \mu \mathrm{M}$ to $100 \mu \mathrm{M})$ were used for 14 days to assess cell viability, which showed no significant change in cell viability. 
IL-1 $\beta$

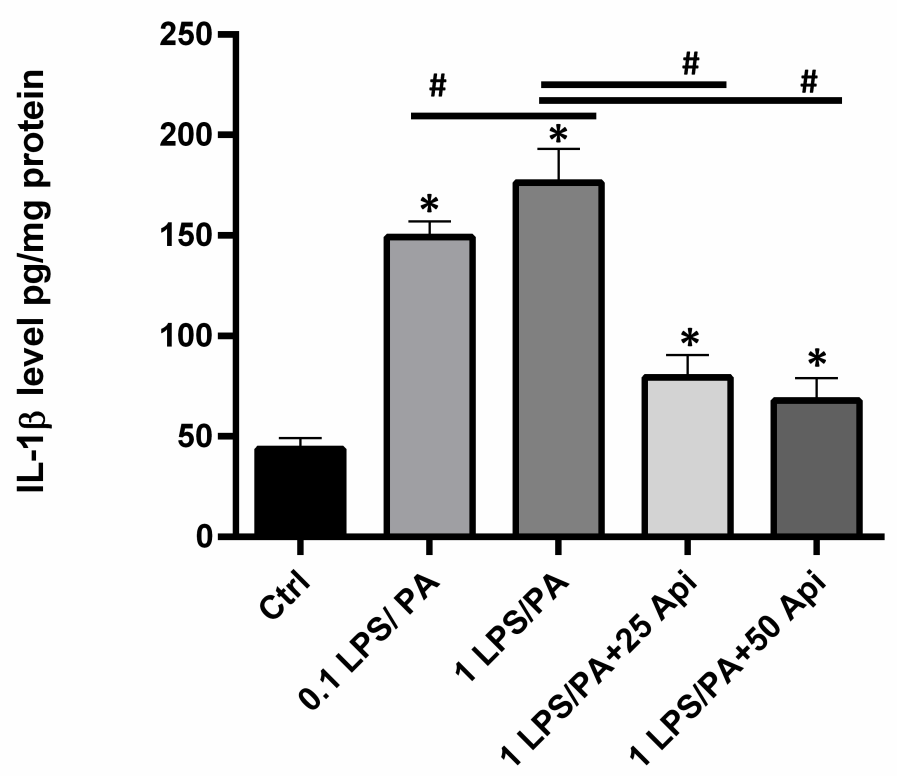

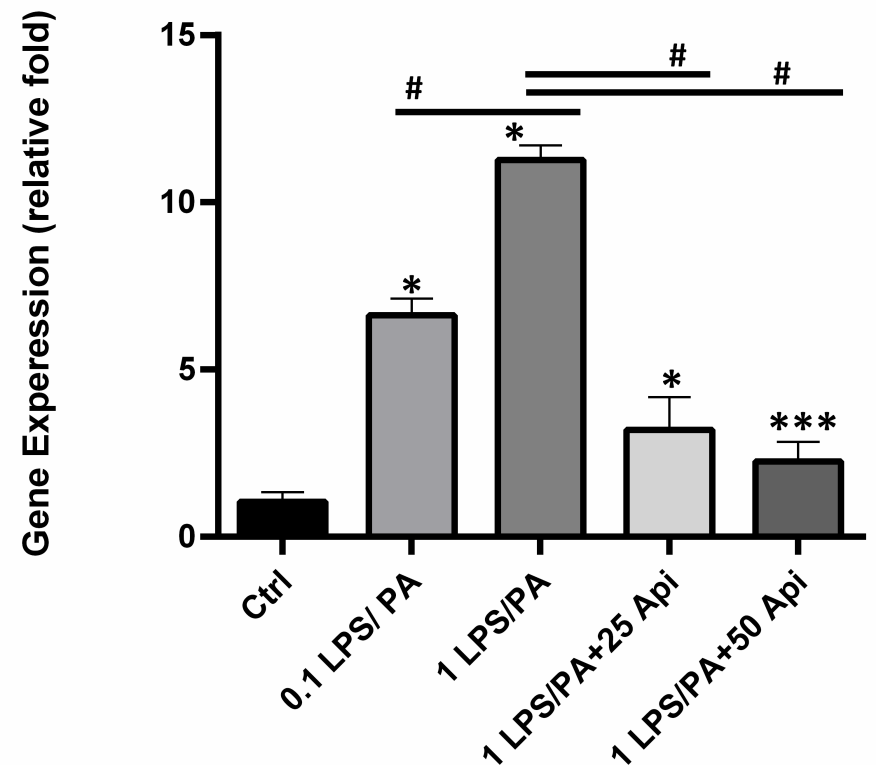

Figure 3

Levels of IL-1 $\beta(A)$, and gene expression of NLRP3 (B) in cultured MSCs in the presence and absence of LPS/PA and Apigenin. LPS/PA: MSCs received 0.1 mg.ml-1 LPS/0.25 mM PA, 1 LPS/PA: MSCs received 1 mg.ml-1 LPS/0.25 mM PA, 1 LPS/PA + 25 Api: MSCs received 0.1 mg.ml- 1 LPS/0.25 mM PA and $25 \mu M$ apigenin, 1LPS/PA + 50 Api: MSCs received $0.1 \mathrm{mg} . \mathrm{ml}-1 \mathrm{LPS} / 0.25 \mathrm{mM}$ PA and $50 \mu \mathrm{M}$ apigenin.* $\mathrm{p}<0.001$ v.s Ctrl. ** $p<0.01$ v.s Ctrl. *** $p<0.05$ v.s Ctrl. \# $p<0.001$ v.s 1 LPS/PA. \#\# $p<0.01$ v.s 1 LPS/PA.

A
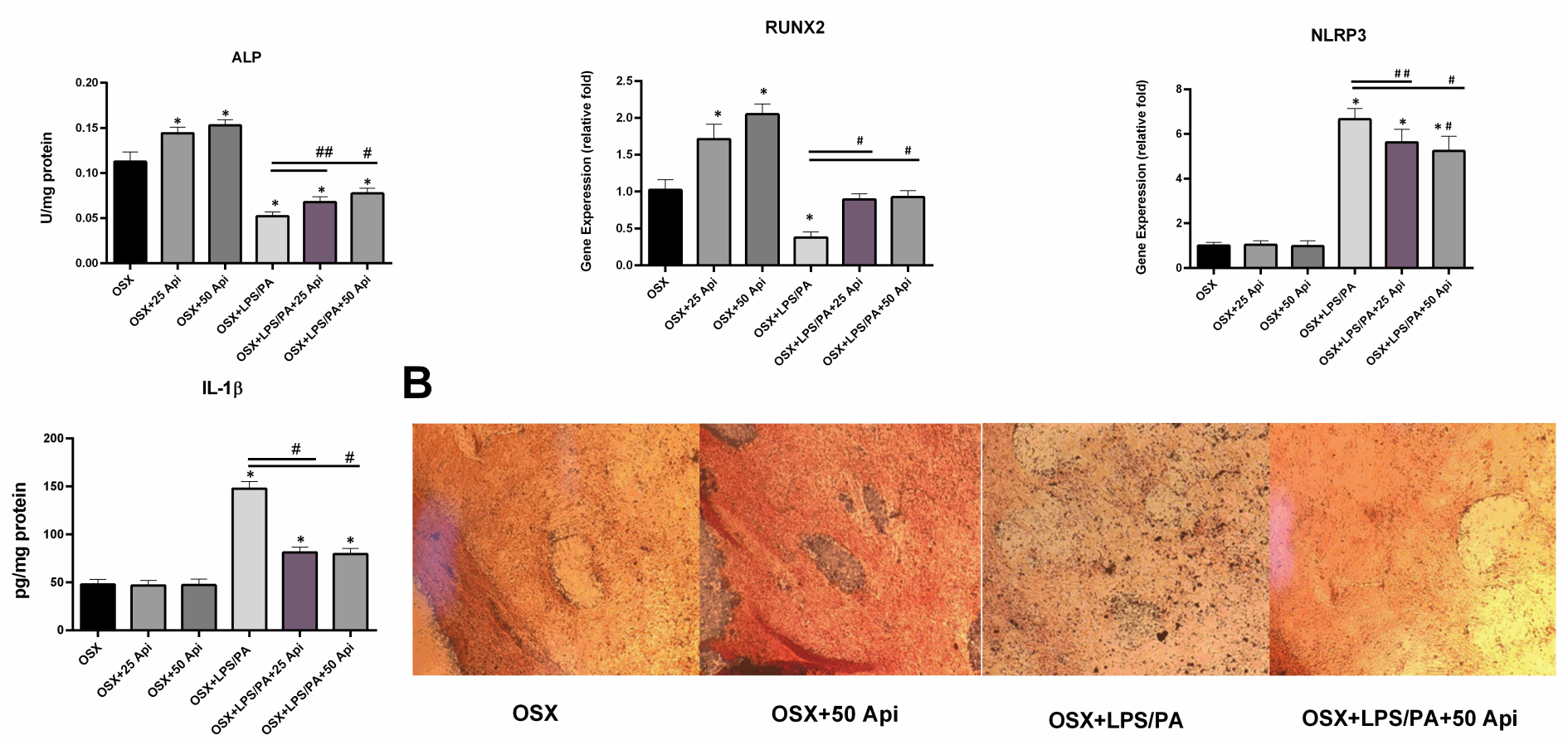


\section{Figure 4}

A: ALP activity, gene expression of RUNX2, Levels of IL-1 $\beta$, and gene expression of NLRP3 in cultured MSCs in the osteogenic medium in the presence and absence of LPS/PA and Apigenin. OSX; MSC cultured in osteogenic medium, OSX+25 Api; MSC cultured in osteogenic medium and treated with $25 \mu \mathrm{M}$ apigenin, OSX+50 Api; MSC cultured in osteogenic medium and treated with $50 \mu \mathrm{M}$ apigenin, OSX+LPS/PA; MSC cultured in osteogenic medium and treated with 1 mg.ml-1 LPS/0.25 mM PA. OSX+LPS/PA+25 Api; ; MSC cultured in osteogenic medium and treated with $1 \mathrm{mg} \cdot \mathrm{ml}-1 \mathrm{LPS} / 0.25 \mathrm{mM}$ PA and $25 \mu \mathrm{M}$ apigenin; OSX+LPS/PA+50 Api; ; MSC cultured in osteogenic medium and treated with 1 mg.ml-1 LPS/0.25 mM PA and $50 \mu \mathrm{M}$ apigenin. B: Alizarin red staining indicates the degree of differentiation of cells in different groups for 21 days. ${ }^{*} p<0.001$ v.s Ctrl. ${ }^{* *} p<0.01$ v.s Ctrl. ${ }^{* \star} p<0.05$ v.s Ctrl. \# p<0.001 v.s 1 LPS/PA. \#\# p<0.01 v.s 1 LPS/PA. 